\title{
Distribution and population genetics of the threatened freshwater crayfish genus
}

\section{Tenuibranchiurus (Decapoda: Parastacidae)}

Kathryn L. Dawkins ${ }^{A^{*}}$, James M. Furse ${ }^{B}$, Clyde H. Wild ${ }^{B}$, Jane M. Hughes ${ }^{C}$

A Australian Rivers Institute, Griffith University, Gold Coast, Qld 4222, Australia.

${ }^{B}$ Environmental Futures Centre, Griffith University, Gold Coast, Qld 4222, Australia.

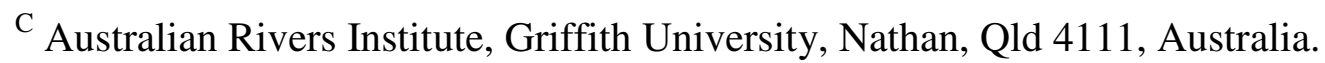

* Corresponding author: Tel: +61 755528140

Email: k.dawkins@griffith.edu.au

10

Abstract. Very high rates of extinction are recorded in freshwater ecosystems, with coastally distributed species threatened by urban development, pollution and climate change. One example, the world's second smallest freshwater crayfish (genus Tenuibranchiurus), inhabits coastal swamps in central-eastern Australia. Although 15 only one species is described (Tenuibranchiurus glypticus), it was expected that populations isolated through habitat fragmentation would be highly divergent. The aims of this study were to determine if: populations of Tenuibranchiurus are genetically distinct, and if ancient divergence, as indicated in other species in the region, was evident. Tenuibranchiurus were collected at seven sites, extending the known geographical distribution $\sim 260 \mathrm{~km}$ south to Wooli, NSW. Analysis of two mitochondrial DNA gene regions indicated two highly divergent clades, with numerous additional sub-clades. Both clades and sub-clades were strongly congruent with geographical location, and were estimated to have diverged from each other during the Miocene/Pliocene era. Little sharing of haplotypes between subpopulations was evident, indicating negligible gene flow, and genetic differentiation between sub-clades possibly indicates distinct species. The coastal distribution of Tenuibranchiurus, severe habitat fragmentation and clear differences between subclades suggests they should be recognised as evolutionarily significant units, and be treated as such if conservation and management initiatives are warranted. 


\section{Introduction}

With extinctions occurring in freshwater ecosystems faster than any other habitat (Ricciardi and Rasmussen 1999; Loh 2002; Jenkins 2003), it is critical to understand current patterns of diversity in our rivers and streams. High levels of cryptic diversity have been found in many freshwater species (Baker et al. 2003; Baker et al. 2004; Cook et al. 2006) and in many cases, these cryptic species appear to have diverged during the Miocene or Pliocene. Despite similar morphologies, they often have different distributions from one another (Chenoweth and Hughes 2003; Cook et al. 2006; Page and Hughes 2007). It is vital to determine the levels of cryptic diversity and the patterns of distribution for freshwater species to conserve and maintain biodiversity. If these factors are ignored, it is likely that management plans will be ineffective and possibly result in loss of species (Margules and Pressey 2000; Cook et al. 2008a).

45 One practice for maintaining the evolutionary heritage of populations is through the identification of evolutionarily significant units (ESUs). There are many definitions as to what constitutes an ESU; however, Moritz (1994) attempted an operational definition, specifying that ESUs should be "reciprocally monophyletic for mtDNA and show significant divergence of allele frequencies at nuclear loci”. Based on this definition, many ESUs have been identified within previously described crayfish species, including Cherax tenuimanus (Smith) from Western Australia (Nguyen et al. 2002), and Austropotamobius pallipes (Lereboullet) from France (Gouin et al. 2006), Italy (Fratini et al. 2005) and the Iberian Peninsula (Dieguez-Uribeondo et al. 2008).

In Australia, freshwater crayfish are of particular interest because a number of species inhabit small coastal streams throughout Queensland (Qld) and New South Wales (NSW). Much of their habitat is highly fragmented, often separated by extensive areas of unsuitable or degraded habitat (mostly urban development). Many of these species are habitat specialists and are often geographically isolated from one another,

60 a situation likely to lead to genetic divergence and possibly speciation over evolutionary time. Studies on a number of freshwater species in the region have shown evidence of high levels of genetic divergence among some populations as well as phylogeographic breaks along the NSW and Qld border, including Macrobrachium australiense Holthius (Carini and Hughes 2004; Sharma and Hughes 2009), Cherax 

and Nannoperca oxleyana Whitley (Hughes et al. 1999; Knight et al. 2009). Because previous studies demonstrate that these organisms living in coastal habitats exhibit high levels of genetic divergence, it is likely that Tenuibranchiurus, a genus of freshwater crayfish confined to the same coastal habitat (i.e. a similar distribution), also consists of a series of genetically divergent populations.

Tenuibranchiurus (Decapoda: Parastacidae) is a little known freshwater crayfish genus found along the central eastern coast of Australia (Riek 1969). It is regarded as the second smallest freshwater crayfish worldwide, reaching a maximum total length of only 25 mm (Riek 1969; Crandall 2002). Studies on Tenuibranchiurus to date have concentrated mainly on taxonomic and phylogenetic relationships with other Australian crayfish genera, rendering the genus poorly understood at a basic level. For example, there has been no concentrated efforts to determine the actual distribution of the genus, and almost no information is available on its basic biology and ecology, with only two studies on the general behaviour of Tenuibranchiurus (Harding and Williamson 2003; Harding and Williamson 2004).

There is currently one species described in this genus, Tenuibranchiurus glypticus Riek, but the presence of two additional species has been suggested on the basis of morphological differences (Horwitz 1995). As a result of long-term historical geographic isolation, sub-populations of Tenuibranchiurus may have undergone genetic divergence, possibly resulting in genetically distinct species within this genus. Currently, this genus has no conservation status assigned to it, and is only protected where it occurs in National Parks and other conservation areas. Appreciable areas of its habitat have been cleared for development such as housing, business and infrastructure (Joyce 2006). Therefore, the genus may require protection due to significant and continuing habitat loss restricting and reducing its distribution and eliminating isolated sub-populations. However, Tenuibranchiurus may also warrant conservation efforts on the basis of geographically isolated sub-populations qualifying as ESUs (as defined by Moritz 1994). Therefore, the aims of this study were to investigate (1) if sub-populations of Tenuibranchiurus are genetically isolated from one another; and (2) if there is evidence of ancient divergence as has been demonstrated for other aquatic species occupying similar coastal habitat in this region. 


\section{Materials and methods}

Tenuibranchiurus is an unremarkable grey-brown crayfish that is cryptic in habit (Riek 1951). The genus was first described from two locations, Mt Gravatt and Caloundra, Qld, by Riek (1951). Since then, the genus has been reported from a total of five locations within Qld; Bells Creek (Crandall et al. 1999; Schultz et al. 2007;

105 Schultz et al. 2009), Eumundi, Mooloolaba, Kinkuna National Park (Schultz et al. 2007) and Bribie Island (Harding and Williamson 2003; Schultz et al. 2009), and also in ‘far north-eastern' NSW (Horwitz 1995) (Fig. 1B).

Tenuibranchiurus inhabits coastal wallum/Melaleuca swamps where they are thought

110 to construct deep burrows in the soil (Riek 1951). Tenuibranchiurus can be readily distinguished from most other crayfish in the region by the position of the chelae, which are orientated vertically instead of horizontally (Riek 1969). They are quite similar in morphology to the genus Engaeus (from Tasmania and Victoria), but differ in branchial and abdominal structure (Riek 1951; Riek 1969). Although

115 Tenuibranchiurus resemble Engaeus in form, they are genetically more closely related to the genus Geocharax (from Tasmania and Victoria), being placed "sister" to these in a study undertaken by Schultz et al. (2007).

\section{Sampling methods}

120 Sampling was carried out during the day from January to May 2008. Sites of potential habitat for Tenuibranchiurus were identified from digital vegetation maps detailing coastal Melaleuca swamp distributions. Additional sites that appeared to be suitable habitat were also identified opportunistically while in the field. Tenuibranchiurus were collected from swamps by sweep netting, pumping out

125 burrows with a bait-pump and baited traps. Where the bait-pump could not be used efficiently (e.g. tree roots obstructing pump), hand excavation of the burrows was undertaken. Where possible, a minimum of five individuals were collected from each site as this sample size has been considered in other studies to be sufficient to provide a robust genetic analysis to identify deep levels of genetic divergence (e.g. Ponniah and Hughes 2004). Live specimens were stored separately on ice in the field, frozen at $-20^{\circ} \mathrm{C}$ on return to the laboratory, and preserved separately in $70 \%$ ethanol. Fifty- 
one Tenuibranchiurus were collected over seven field sites and retained for genetic analysis.

DNA extraction, amplification and sequencing

The DNA from each specimen was extracted using a variation of the CTAB/phenolchloroform extraction protocol (Doyle and Doyle 1987). Two mitochondrial regions were amplified; cytochrome oxidase subunit 1 (COI) using the primers CRCOI-F (5'CWACMAAYCATAAAGAYATTGG-3') and CRCOI-R (5'-

140 GCRGANGTRAARTARGCTCG-3') (Cook et al. 2008b), and 16S using the primers 16S-ar (5'-CGCCTGTTTATCAAAAACAT-3') and 16S-br (5'CCGGTCTGAACTCAGATCACGT-3') (Palumbi et al. 1991).

The PCR reactions for both COI and 16S used the following; $2.0 \mu \mathrm{L}$ DNA extract, 0.4 $145 \mu \mathrm{L}$ forward primer, $0.4 \mu \mathrm{L}$ reverse primer, $0.3 \mu \mathrm{L} d \mathrm{dTP}, 0.63 \mu \mathrm{L} \mathrm{MgCl}_{2}(50 \mathrm{mM})$,

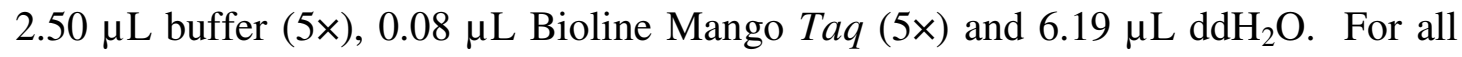
analyses, one positive and one negative control were included, with PCR reactions performed on a GeneAmp PCR System 2700 (Applied Biosystems, www.appliedbiosystems.com). The PCR program used for COI samples consisted of 150 the following conditions: $94^{\circ} \mathrm{C}$ for $5 \mathrm{~min}$; 40 cycles of: $30 \mathrm{sec}$ at $94^{\circ} \mathrm{C}, 30 \mathrm{sec}$ at $55^{\circ} \mathrm{C}$, $1 \mathrm{~min}$ at $72^{\circ} \mathrm{C}$; then $7 \mathrm{~min}$ at $72^{\circ} \mathrm{C}$ with the reaction stored at $4^{\circ} \mathrm{C}$ until further analysis. The program used to amplify $16 \mathrm{~S}$ samples was: $94^{\circ} \mathrm{C}$ for $10 \mathrm{~min} ; 40$ cycles of: $45 \mathrm{sec}$ at $94^{\circ} \mathrm{C}, 45 \mathrm{sec}$ at $52^{\circ} \mathrm{C}, 1.5 \mathrm{~min}$ at $72^{\circ} \mathrm{C}$; then $7 \mathrm{~min}$ at $72^{\circ} \mathrm{C}$ with the reaction stored at $4^{\circ} \mathrm{C}$ until further analysis.

An enzymatic purification procedure was undertaken using EXO SAP (Fermentas, www.fermentas.com) on successfully amplified samples. Purifications were performed in $6.25-\mu \mathrm{L}$ reaction volumes containing the following: $0.25 \mu \mathrm{L}$ Exonuclease I, 1.0 $\mu \mathrm{L}$ Shrimp Alkaline Phosphate and 5.0 $\mu \mathrm{L}$ amplified PCR product.

160 The resulting solution was incubated at $37^{\circ} \mathrm{C}$ for $35 \mathrm{~min}$, heated at $80^{\circ} \mathrm{C}$ for $20 \mathrm{~min}$, held at $15^{\circ} \mathrm{C}$, then stored at $4^{\circ} \mathrm{C}$ until further analysis. Sequencing reactions contained $1.0 \mu \mathrm{L}$ purified PCR product, $5.5 \mu \mathrm{L} \mathrm{ddH}_{2} \mathrm{O}$, 5.0 $\mu \mathrm{L}$ Terminator Mix (Applied Biosystems, www.appliedbiosystems.com), $2.0 \mu \mathrm{L} 5 \times$ Terminator Mix Buffer (Applied Biosystems, www.appliedbiosystems.com) and $1.0 \mu \mathrm{L}$ of the forward 165 primer (CRCOI-F/16S-ar). Reactions were performed under the following conditions: 
initial hold of $96^{\circ} \mathrm{C}$ for $1 \mathrm{~min}$; 30 cycles of: $96^{\circ} \mathrm{C}$ for $10 \mathrm{sec}, 50^{\circ} \mathrm{C}$ for $5 \mathrm{sec}, 60^{\circ} \mathrm{C}$ for $4 \mathrm{~min}$; then a final hold at $4^{\circ} \mathrm{C}$. Samples were then cleaned and subsequently sequenced on an automated sequencing machine (Applied Biosystems 3130, www.appliedbiosystems.com). Sequences were edited using Sequencher 4.1.2

170 (GeneCodes 2000) and aligned using MAFFT version 5.3 (Katoh et al. 2005). A 644bp fragment was used in COI analyses and a 449-bp fragment for 16S analyses.

\section{COI and 165 phylogenetic analyses}

A total of 51 Tenuibranchiurus collected during this study were sequenced for the 175 COI gene fragment, with a subset of 14 sequenced for the $16 \mathrm{~S}$ fragment to examine deeper phylogenetic relationships. Additional sequences obtained from GenBank (see Accessory Publication) were also included in both COI and 16S analyses. For all analyses, Gramastacus sp. sequences were used as an outgroup as this genus (with Engaewa and Geocharax) has been demonstrated as forming a monophyletic clade with Tenuibranchiurus to the "exclusion of all other parastacid genera" (Schultz et al. 2009).

To examine the relationship between Tenuibranchiurus haplotypes, a best-fit model of evolution was first selected for both the COI and $16 \mathrm{~S}$ data sets $(\mathrm{COI}=\mathrm{HKY}+\mathrm{I}+\mathrm{G}$ 185 model; 16S=HKY+G model) using the program jModeltest v. 0.0.1 (Posada 2008). For each data set, three methods were used; neighbour-joining (NJ), maximum likelihood (ML) and maximum parsimony (MP). Both the NJ and MP trees were created using the program PAUP* (Swofford 2003) (1000 bootstrap replicates; full heuristic search), while the ML tree was created using the program RAxML v. 7.0.0

190 (Stamatakis 2006) (1000 bootstrap replicates). Networks showing relationships among haplotypes were also created for the COI data set, using the program TCS v. 1.21 (Clements et al. 2000). Networks were not created for the $16 \mathrm{~S}$ data as only 25 sequences were available for analysis (see Accessory Publication).

\section{Time of divergence}

The time of divergence between identified clades and sub-clades was estimated using a molecular clock approach using MEGA (Tamura et al. 2007). Using a molecular clock approach was considered appropriate as tests performed on both unconstrained and constrained trees showed that they were not significantly different $(p=0.828)$. 
200 The net sequence divergence was calculated (including \pm S.E. to correct for withinclade polymorphisms) and three estimated divergence rates were used for both COI and 16S; COI=2.0\% (Wares and Cunningham 2001), 1.7\% (Schubart et al. 1998) and 1.4\% (Morrison et al. 2004; Page and Hughes 2007); 16S=0.9\% (Sturmbauer et al. 1996; Schultz et al. 2009), 0.65\% (Schubart et al. 1998) and 0.53\% (Stillman and

205 Reeb 2001; Schultz et al. 2009).

\section{Analysis of population structure}

All further statistical analyses were only performed on the COI data as the $16 \mathrm{~S}$ sample sizes were too low for robust analyses. Two tests of neutrality were carried out

210 (Tajima's D (Tajima 1989) and Fu's Fs (Fu and Li 1993)) using Arlequin 3.1 (Excoffier et al. 2005). These tests were used to detect any recent demographic changes (e.g. recent bottlenecks or population expansions) or non-neutral evolution of the COI fragment.

215 As there was no real logic for dividing the sample sites into regions or groups, analysis of molecular variance (AMOVA) was not performed. Instead, pairwise $\Phi_{\mathrm{ST}}$ (genetic structure based on haplotype frequency and genetic divergence) were calculated using Arlequin to determine the level of genetic differentiation between pairs of sites. Where sites were represented by fewer than 5 individuals, they were 220 either pooled (i.e. MA with TCB, GC1 with GC2, BNP1 with BNP 2) to provide a robust analysis, or were removed (i.e. BI). A Mantel test with 1000 permutations was also run in Arlequin to identify any relationships between genetic and geographic distance between Tenuibranchiurus sites, which would be expected if the dispersal distance of individuals is less than the area of the study and the sub-populations have

225 been in their habitat for long enough to have reached equilibrium between migration, mutation and genetic drift (Slatkin 1993). 


\section{Results}

Field summary

In addition to historical locations where Tenuibranchiurus had previously been recorded (see Accessory Publication), seven additional sub-populations were identified (from 31 field sites sampled) with a number of these being outside the previously reported range of Tenuibranchiurus, extending its known distribution. Although all historical sites were visited for sampling, no Tenuibranchiurus were found, either due to habitat loss or lack of water due to drought conditions. In general, site characteristics where crayfish were collected were typical of those previously described in the literature (i.e. coastal wallum/Melaleuca swamp); however, two sites were notably different on the basis that the first (LakeH) was a natural drainage channel in heathland with no Melaleuca present and the second (BNP2) was a deep stream channel, with slow-flowing water, with Melaleuca on the stream banks.

\section{Phylogenetic analysis}

Fifty-one Tenuibranchiurus collected during this study were sequenced for the COI gene fragment, with an additional six Tenuibranchiurus samples obtained from

245 Bentley (2007) and five specimens of Gramastacus sp. which were used as outgroups. Within Tenuibranchiurus COI sequences, 175 of 644 bases were variable with 20, 4 and $1511^{\text {st }}, 2^{\text {nd }}$, and $3^{\text {rd }}$ codon position changes, respectively, and a total of 13 amino acid changes. A total of 154 transitions and 51 transversions were observed across all nucleotide sites, with 158 of these sites parsimony informative. No stop codons were observed in any of the sequences. From the 57 individuals, a total of 28 haplotypes were identified. All of the phylogenetic trees (NJ, ML and MP) inferred from the 28 Tenuibranchiurus haplotypes (with outgroups) suggest the presence of two highly divergent clades (bootstrap values 100\%) with two and three sub-clades, respectively, within each (bootstrap values $\geq 95 \%$ ) (Fig. 1A). Clade 1 consisted of haplotypes from 255 the Qld region, while Clade 2 were those from NSW.

From Sub-clades 1 through 5, three to four representative haplotypes were sequenced for the $16 \mathrm{~S}$ gene fragment. Additional 16S sequences were obtained from GenBank and Bentley (2007) (see Accessory Publication), and four Gramastacus sp. samples

260 were used as 16S outgroups. Within Tenuibranchiurus 16S sequences, 94 of 449 
bases were variable. A total of 85 transitions and 29 transversions were observed across all nucleotide sites. The phylogenetic trees inferred from the 22 Tenuibranchiurus $16 \mathrm{~S}$ haplotypes showed the same two divergent clades, but the subclades were not as clear. However, the same groupings were noted, with Clade 1 comprised of haplotypes found only in Qld and Clade 2 of those from NSW (Fig. 1C).

\section{Haplotype network analysis}

Five COI networks were created (Fig. 1B) using the program TCS. However, these were unable to be joined despite using a cut-off level of $90 \%$. The haplotypes 270 displayed concordance with geographical location of sub-populations (Fig. 1B). Subclade 1 consisted of those individuals found at sites GC1 and GC2 (Gold Coast, Qld), Sub-clade 2 from MA and TCB (Maryborough and Tin Can Bay, Qld), Sub-clade 3 from LakeH, BNP1 and BNP2 (Lake Hiawatha and Broadwater National Park, NSW), Sub-clade 4 from LH (Lennox Heads, NSW), and Sub-clade 5 from BI2 (Bribie 275 Island, Qld).

\section{Time of divergence}

Based on the COI gene, it is estimated that divergences between each of the five Tenuibranchiurus sub-clades occurred during the Miocene (5 - 23mya) and Pliocene 280 era (1.8 - 5mya) (Table 1). The most recent split was between Sub-clades 2 and 5 (2.5 - 3.5mya), with the earliest between Sub-clades 1 and 3 (11.1 - 15.9mya). As the $16 \mathrm{~S}$ gene fragment was used to examine deeper phylogenetic relationships, the time of divergence was only estimated between the two major clades (Clades 1 and 2). The time of divergence was placed 16.1 - 27.4mya, which was slightly older than the estimate based on COI (8.0 - 11.4mya).

\section{Analysis of population structure}

Tajima's $D$ test of neutrality was non-significant for all sub-clades, while Fu's $F s$ was only significant for Sub-clade $1(p<0.02)$ (Table 2). All pairwise $\Phi_{\mathrm{ST}}$ comparisons 290 were significant $(p<0.001)$, with values 0.77 or greater indicating very little or no gene flow between sites (Table 3). The Mantel test showed a weak but significant relationship between the $\Phi_{\mathrm{ST}}$ and geographical distance $(p=0.044)$. 


\section{Discussion}

This study extends the distribution of Tenuibranchiurus appreciably ( 260 km), with

this genus not previously recorded on the Gold Coast in Qld or as far south as Wooli, NSW. The total known range now extends approximately $600 \mathrm{~km}$ north-south, and it is possible that the distribution extends further north and south of these present limits. Also, LakeH and BNP2 were markedly different from the other sites sampled, indicating that habitat previously thought unsuitable for Tenuibranchiurus (i.e. Riek 1951) may in fact be suitable for this genus.

\section{Genetic isolation of Tenuibranchiurus sub-populations}

The results of the pairwise $\Phi_{\mathrm{ST}}$ analysis suggest high levels of genetic diversity and very little or no gene flow between Tenuibranchiurus sub-populations. Similar results

305 have also been reported for other organisms that have experienced some form of population separation and are found in similar habitats to Tenuibranchiurus. For example, very low levels of dispersal between sub-populations of the Oxleyan pygmy perch (Nannoperca oxleyana) have been reported, with $\Phi_{\mathrm{ST}}$ values between 0.25 and 0.91 (Hughes et al. 1999). Bentley et al. (2010) also examined levels of gene flow

310 within four clades of Cherax dispar and found very little gene flow between subpopulations ( $\Phi_{\mathrm{ST}}$ between 0.33 and 0.83$)$.

All but one of the Tajima's $D$ and Fu's $F s$ tests of neutrality were non-significant $(F s=-4.10, p<0.02)$. Although this value is significant, it is small compared to values 315 found in other studies (up to -72.7) (Mills et al. 2008). Taken together, the results of these tests suggest there is no evidence of recent bottlenecks or population expansions within the five sub-clades tested. There is very little sharing of haplotypes between sub-populations, indicating that at least female dispersal rates are very low, which is not surprising due to the large geographic distances that separate sub-populations. As

320 mtDNA was analysed for this study, no conclusions can be made as to the movements of the male individuals, as mtDNA is maternally inherited (Hartl and Clark 2007). Nevertheless, there is no reason to suspect male-biased dispersal in these crayfish.

\section{Time of divergence}

325 Both the COI and $16 \mathrm{~S}$ trees show a clear separation between Clade 1 and Clade 2. This is interesting, as Clade 1 is comprised of samples from Qld and Clade 2 of 
samples from NSW. The separation is quite large, almost as large as the separation between the Tenuibranchiurus samples and the outgroup (Gramastacus sp.). This extensive divergence may be due to a long-term barrier. It is possible that the mountain ranges that occur on the border of Qld and NSW have restricted the movement of individuals between northern and southern regions. The analysis of sequence variation in the COI gene fragment also shows clear differences between the sub-clades identified. Similar relationships between sub-clades were also evident for the $16 \mathrm{~S}$ gene. Also, the $16 \mathrm{~S}$ phylogenetic tree shows that the samples obtained from the T. glypticus type locality (Sub-clade 8; Bells Creek, Caloundra) are distinct from other groupings evident within Clade 1.

Both the COI and 16S data sets suggest that Tenuibranchiurus sub-clades diverged during the Miocene/Pliocene era. There has been one other study that has suggested 340 that the geological age of Tenuibranchiurus is only as old as the Holocene era (i.e. 12000ya - present) based on morphological characteristics (Rode and Babcock 2003); however, the estimates obtained from this study clearly indicate that Tenuibranchiurus is far older, and the analyses show that the oldest divergence occurs between Qld and NSW. Another genus of crayfish, Euastacus, which occupies high

345 altitude areas in eastern Australia, has been shown to have diverged more recently, during the Pliocene era (Ponniah and Hughes 2004). This was surprising as there are several clearly morphologically recognised species within the genus Euastacus, in contrast to the one recognised Tenuibranchiurus species. It is possible that further investigation of the morphology and taxonomy of Tenuibranchiurus may indicate at 350 least two distinct species within this genus (i.e. Clades 1 and 2) if not more. Other freshwater crustaceans with a coastal distribution in this region (e.g. freshwater shrimp; Caridina indistincta Calman) have been found to have similar divergence times to those found for Tenuibranchiurus. Caridina indistincta inhabits coastal streams within south-east Qld, Australia, and divergence times between cryptic 355 species fall within the Miocene era (estimates from 6.45 - 11.3mya) (Chenoweth and Hughes 2003; Page and Hughes 2007). Similarly, identified lineages within the shrimp species Paratya australiensis Kemp collected from south-east Qld and NSW have also been found to have diverged during the late Miocene/Pliocene (3.86 11.32mya) (Cook et al. 2006). 


\section{Implications for management}

The distinct separation between Tenuibranchiurus sub-clades is indicative of high genetic divergence. Also, each of the sub-clades consisted of haplotypes collected from only one or two nearby locations. The implication of this is that if sub-

365 populations within a sub-clade were to be lost, it is likely that the genetic information contained within that sub-population would not be found in any other. The large geographic distances between sub-populations and the high levels of genetic divergence between them also indicate that it is very unlikely that these areas could be naturally recolonised following any local extinction events.

The increasing occurrence of habitat destruction, degradation and fragmentation as a result of anthropogenic influences highlights this as being a very real threat to these isolated populations (e.g. Taylor et al. 2007). Although some crayfish are highly mobile organisms that can, given time, disperse over quite large distances (Lindqvist

375 and Huner 1999; Hughes and Hillyer 2003), the small size of this crayfish and low levels of habitat connectivity between sub-populations greatly reduce any possibility of gene flow or movement between them.

In light of the genetic differentiation between the sub-clades, it is appropriate that they

380 be considered ESUs for management and conservation purposes. Also, according to Moritz (1994), Lake Hiawatha from Sub-clade 3 should be considered a separate management unit, and should be treated as such if conservation and management plans are to be applied. It is likely that management plans and conservation efforts will be needed in the future, if not immediately, as there have already been population 385 reductions. For example, one of the type localities for $T$. glypticus has been developed for housing (sites in Mt Gravatt; Riek 1951) with the sub-populations previously located there most likely having been eliminated.

Due to the genetic divergence detected, it is recommended that a thorough 390 examination of the nuclear genetic makeup and morphology of individuals within each Tenuibranchiurus sub-clade be undertaken as it is possible that each of these represents a distinct species. Many studies have used genetic analysis to identify new species, and have gone on to use this information to recognise ESUs and make recommendations for conservation and management plans (Austin and Ryan 2002; de 
395 Bruyn et al. 2004; Santos 2006). In light of this, examination of the morphology and possible description of new species within the genus should be a priority area for future research.

\section{Acknowledgements}

400 This study was conducted as a major part of a B.Sc. (Hons) by Kathryn Dawkins under the supervision of James Furse, Prof. Jane Hughes and Assoc. Prof. Clyde Wild. Funding for this study was provided by both the Australian Rivers Institute and the Griffith School of Environment, Griffith University. Additional funding for genetic analysis was also provided by Rob McCormack and his company 'AABio' and was greatly appreciated. The authors would like to thank the two anonymous reviewers and the associate editor for their helpful comments, Michael Arthur for statistical guidance and Rob McCormack, Jason Coughran and many other volunteers for field assistance. Crayfish were collected under NSW Scientific Collection Permit P05/0077-3.1 and Qld General Fisheries Permit \#91210. 


\section{References}

Austin, C. M., and Ryan, S. G. (2002). Allozyme evidence for a new species of freshwater crayfish of the genus Cherax Erichson (Decapoda : Parastacidae) from the south-west of Western Australia. Invertebrate Systematics 16, 357-367.

Baker, A. M., Williams, S. A., and Hughes, J. M. (2003). Patterns of spatial genetic structuring in a hydropsychid caddisfly (Cheumatopsyche sp. AV1) from southeastern Australia. Molecular Ecology 12, 3313-3324.

Baker, A. M., Hughes, J. M., Dean, J. C., and Bunn, S. E. (2004). Mitochondrial DNA reveals phylogenetic structuring and cryptic diversity in Australian freshwater macroinvertebrate assemblages. Marine and Freshwater Research 55, 629-640.

Bentley, A. (2007). Phylogeographic structure of freshwater crayfish of the genus Cherax (Decapoda: Parastacidae) on the mainland and islands of southeast Queensland. BSc (Hons) Thesis, Griffith University, Nathan.

Bentley, A. I., Schmidt, D. J., and Hughes, J. M. (2010). Extensive intraspecific genetic diversity of a freshwater crayfish within a biodiversity hotspot. Freshwater Biology (In press).

Bentley, A. I., Schmidt, D. J., and Hughes, J. M. (in press). Extensive intraspecific genetic diversity of a freshwater crayfish within a biodiversity hotspot. Freshwater Biology (In press).

Carini, G., and Hughes, J. M. (2004). Population structure of Macrobrachium australiense (Decapoda: Palaemonidae) in Western Queensland, Australia: the role of contemporary and historical processes. Heredity 93, 350-363.

Chenoweth, S. F., and Hughes, J. M. (2003). Speciation and phylogeography in Caridina indistincta, a complex of freshwater shrimps from Australian heathland streams. Marine and Freshwater Research 54, 807-812.

445 Clements, M., Posada, D., and Crandall, K. A. (2000). TCS: a computer program to estimate gene genealogies. Molecular Ecology 9, 1657-1660.

Cook, B. D., Baker, A. M., Page, T. J., Grant, C., Fawcett, J. H., et al. (2006). Biogeographic history of an Australian freshwater shrimp, Paratya australiensis 450 (Atyidae): the role life history transition in phylogeographic diversification. Molecular Ecology 15, 1083-1093.

Cook, B. D., Page, T. J., and Hughes, J. M. (2008a). Importance of cryptic species for identifying 'representative' units of biodiversity for freshwater conservation. Biological Conservation 141, 2821-2831.

Cook, B. D., Pringle, C. M., and Hughes, J. M. (2008b). Molecular evidence for sequential colonization and taxon cycling in freshwater decapod shrimps on a Caribbean island. Molecular Ecology 17, 1066-1075. 
Crandall, K. A., Fetzner, J. W., Lawler, S. H., Kinnersley, M., and Austin, C. M. (1999). Phylogenetic relationships among the Australian and New Zealand genera of freshwater crayfishes (Decapoda: Parastacidae). Australian Journal of Zoology 47, 199-214.

Crandall, K. A. (2002). Crayfish as model organisms. Freshwater Crayfish 13, 3-10.

de Bruyn, M., Wilson, J. A., and Mather, P. B. (2004). Huxley's line demarcates extensive genetic divergence between eastern and western forms of the giant freshwater prawn, Macrobrachium rosenbergii. Molecular Phylogenetics and Evolution 30, 251-257.

Dieguez-Uribeondo, J., Royo, F., Souty-Grosset, C., Ropiquet, A., and Grandjean, F. (2008). Low genetic variability of the white-clawed crayfish in the Iberian Peninsula:

475 its origin and management implications. Aquatic Conservation: Marine and Freshwater Ecosystems 18, 19-31.

Doyle, J. J., and Doyle, J. L. (1987). A rapid DNA isolation procedure for small quantities of leaf tissue. Phytochemistry Bulletin 19, 11-15.

Excoffier, L., Laval, G., and Schneider, S. (2005). Arlequin ver. 3.0: An integrated software package for population genetics data analysis. Evolutionary Bioinformatics Online 1, 47-50.

485 Fratini, S., Zaccara, S., Barbaresi, S., Grandjean, F., Souty-Grosset, C., et al. (2005). Phylogeography of the threatened crayfish (genus Austropotamobius) in Italy: implications for its taxonomy and conservation. Heredity 94, 108-118.

Fu, Y.-X., and Li, W.-L. (1993). Statistical tests of neutrality of mutations. Genetics 490 133, 693-709.

GeneCodes (2000). 'Sequencher (Version 4.1.2).' (Gene Codes Corporation: Ann Arbor, Michigan.)

495 Gouin, N., Grandjean, F., and Souty-Grosset, C. (2006). Population genetic structure of the endangered crayfish Austropotamobius pallipes in France based on microsatellite variation: biogeographical inferences and conservation implications. Freshwater Biology 51, 1369-1387.

500 Harding, D., and Williamson, I. (2003). A note on the habitat requirements of the swamp crayfish on Bribie Island, southeastern Queensland. Memoirs of the Queensland Museum 49, 452.

Harding, D., and Williamson, I. (2004). The influence of light phase and predators on the behaviour of swamp crayfish. Memoirs of the Queensland Museum 49, 704.

Hartl, D. L., and Clark, A. G. (2007). 'Principles of Population Genetics.' 4th Edn. (Sinauer Associates Inc. Publishers: Massachusetts.) 
510 Horwitz, P. (1995) A preliminary key to the species of Decapoda (Crustacea: Malacostraca) found in Australian inland waters. Co-operative Research Centre for Freshwater Ecology, Albury, Australia.

Hughes, J. M., Ponniah, M., Hurwood, D. A., Chenoweth, S. F., and Arthington, A. 515 (1999). Strong genetic structuring in a habitat specialist, the Oxleyan Pygmy Perch Nannoperca oxleyana. Heredity 83, 5-14.

Hughes, J. M., and Hillyer, M. J. (2003). Patterns of connectivity among populations of Cherax destructor (Decapoda: Parastacidae) in western Queensland, Australia. Marine and Freshwater Research 54, 587-596.

Jenkins, M. (2003). Prospects for biodiversity. Science 302, 1175-1177.

Joyce, K. (2006) Wetland Management Profile; Coastal melaleuca swamp wetlands. 525 Ecosystem Conservation Branch, EPA, Queensland.

Katoh, K., Kuma, K.-I., Toh, H., and Miyata, T. (2005). MAFFT version 5: improvement in accuracy of multiple sequence alignment. Nucleic Acids Research 33, 511-518.

Knight, J. T., Nock, C. J., Elphinstone, M. S., and Baverstock, P. R. (2009). Conservation implications of distinct genetic structuring in the endangered freshwater fish Nannoperca oxleyana (Percichthyidae). Marine and Freshwater Research 60, 3444.

Lindqvist, O. V., and Huner, J. V. (1999). Life history characteristics of crayfish: What makes some of them good colonizers? In 'Biotic Interactions and Global Change'. (Eds P. Kareiva, J. Kingsolver and R. Huey.) pp. 23-30. (Sinauer Associates, Inc.: Sunderland Mass.)

Loh, J. (2002). 'Living Planet Report 2002.' (World Wide Fund for Nature (WWF) International: Gland, Switzerland.)

Margules, C. R., and Pressey, R. L. (2000). Systematic conservation planning. Nature 545 405, 243-253.

Mills, C. E., Hadwen, W. L., and Hughes, J. M. (2008). Looking through glassfish: marine genetic structure in an estuarine species. Marine and Freshwater Research 59, 627-637.

Moritz, C. (1994). Defining 'evolutionarily significant units' for conservation. Trends in Ecology \& Evolution 9, 373-375.

Morrison, C. L., Rios, R., and Duffy, J. E. (2004). Phylogenetic evidence for an ancient rapid radiation of Caribbean sponge-dwelling snapping shrimps (Synalpheus). Molecular Phylogenetics and Evolution 30, 563-581. 
Nguyen, T. T. T., Meewan, M., Ryan, S., and Austin, C. M. (2002). Genetic diversity and translocation in the marron, Cherax tenuimanus (Smith): implications for management and conservation. Fisheries Management and Ecology 9, 163-173.

Page, T. J., Sharma, S., and Hughes, J. M. (2004). Deep phylogenetic structure has conservation implications for ornate rainbow fish (Melanotaeniidae: Rhadinocentrus ornatus) in Queensland, eastern Australia. Marine and Freshwater Research 55, 165 172.

Page, T. J., and Hughes, J. M. (2007). Phylogeographic structure in an Australian freshwater shrimp largely pre-dates the geological origins of its landscape. Heredity 98, 222-231.

Palumbi, S. R., Martin, A., Romano, S., McMillan, W. O., Stice, L., et al. (1991). 'The Simple Fool's Guide to PCR.' (University of Hawaii Press: Honolulu.)

Ponniah, M., and Hughes, J. M. (2004). The evolution of Queensland spiny mountain crayfish of the genus Euastacus. I. Testing vicariance and dispersal with interspecific mitochondrial DNA. Evolution 58, 1073-1085.

Posada, D. (2008). jModelTest: Phylogenetic Model Averaging. Molecular Biology and Evolution 25, 1253-1256.

Ricciardi, A., and Rasmussen, J. B. (1999). Extinction rates of North American freshwater fauna. Conservation Biology 13, 1220-1222.

Riek, E. F. (1951). The freshwater crayfish (family Parastacidae) of Queensland, with an appendix describing other Australian species. Records of the Australian Museum 22, 368-388.

Riek, E. F. (1969). The Australian freshwater crayfish (Crustacea: Decapoda: Parastacidae), with descriptions of new species. Australian Journal of Zoology 17, $590 \quad 855-918$.

Rode, A. L., and Babcock, L. E. (2003). Phylogeny of fossil and extant freshwater crayfish and some closely related nephropid lobsters. Journal of Crustacean Biology 23, 418-435.

Santos, S. R. (2006). Patterns of genetic connectivity among anchialine habitats: a case study of the endemic Hawaiian shrimp Halocaridina rubra on the island of Hawaii. Molecular Ecology 15, 2699-2718.

600 Schubart, C. D., Diesel, R., and Hedges, S. B. (1998). Rapid evolution to terrestrial life in Jamaican crabs. Nature 393, 363-365.

Schultz, M. B., Smith, S. A., Richardson, A. M. M., Horwitz, P., Crandall, K. A., et al. (2007). Cryptic diversity in Engaeus Erichson, Geocharax Clark and Gramastacus

605 Riek (Decapoda: Parastacidae) revealed by mitochondrial 16S rDNA sequences. Invertebrate Systematics 21, 569-587. 
Schultz, M. B., Smith, S. A., Horwitz, P., Richardson, A. M. M., Crandall, K. A., et al. (2009). Evolution underground: A molecular phylogenetic investigation of

610 Australian burrowing freshwater crayfish (Decapoda: Parastacidae) with particular focus on Engaeus Erichson. Molecular Phylogenetics and Evolution 50, 580-598.

Sharma, S., and Hughes, J. M. (2009). Genetic structure and phylogeography of freshwater shrimps (Macrobrachium australiense and Macrobrachium tolmerum): the 615 role of contemporary and historical events. Marine and Freshwater Research 60, 541553.

Slatkin, M. (1993). Isolation by distance in equilibrium and non-equilibrium populations. Evolution 47, 264-279.

Stamatakis, A. (2006). RAxML-VI-HPC: Maximum likelihood-based phylogenetic analyses with thousands of taxa and mixed models. Bioinformatics 22, 2688-2690.

Stillman, J. H., and Reeb, C. A. (2001). Molecular phylogeny of eastern Pacific porcelain crabs, genera Petrolisthes and Pachycheles, based on the mtDNA 16S rDNA sequence: phylogeographic and systematic implications. Molecular Phylogenetics and Evolution 19, 236-245.

Sturmbauer, C., Leninton, J. S., and Christy, J. (1996). Molecular phylogeny analysis 630 of fiddler crabs: Test of the hypothesis of increasing behavioral complexity in evolution. Proceedings of the National Academy of Sciences USA 93, 10855-10857.

Swofford, D. L. (2003). 'PAUP*. Phylogenetic Analysis Using Parsimony (*and other methods) (Version 4).' (Sinauer Associates: Sunderland, Massachusetts.)

Tajima, F. (1989). Statistical method for testing the neutral mutation hypothesis by DNA polymorphism. Genetics 123, 585-595.

Tamura, K., Dudley, J., Nei, M., and Kumar, S. (2007). MEGA 4: Molecular 640 Evolutionary Genetics Analysis (MEGA) software version 4.0. Molecular Biology and Evolution 24, 1596-1599.

Taylor, C. A., Schuster, G. A., Cooper, J. E., DiStefano, R. J., Eversole, A. G., et al. (2007). A reassessment of the conservation status of crayfishes of the United States 645 and Canada after 10+ years of increased awareness. Fisheries 32, 372-389.

Wares, J. P., and Cunningham, C. W. (2001). Phylogeography and historical ecology of the North Atlantic intertidal. Evolution 55, 2455-2469. 
Table 1. Estimated time of divergence between clades based on the CO1 gene. Mean net distance calculated using the Tamura-Nei model with a gamma distribution. Timing and error to the nearest one hundred thousand years. $\mathrm{SC}=$ sub-clade. Timing ${ }^{1}=0.020$ per myr, ${ }^{2}=0.017$ per myr, ${ }^{3}=0.014$ per myr

\begin{tabular}{ccccccccc}
\hline Comparison & $\begin{array}{c}\text { Mean } \\
\text { net } \\
\text { distance }\end{array}$ & $\begin{array}{c}\text { Standard } \\
\text { error }\end{array}$ & $\begin{array}{c}\text { Timing } \\
\text { (myrs) }\end{array}$ & $\begin{array}{c}\text { Error } \\
(\text { myrs })\end{array}$ & $\begin{array}{c}\text { Timing } \\
(\mathrm{myrs})\end{array}$ & $\begin{array}{c}\text { Error } \\
\text { (myrs) }\end{array}$ & $\begin{array}{c}\text { Timing }^{3} \\
(\mathrm{myrs})\end{array}$ & $\begin{array}{c}\text { Error }^{2} \\
(\mathrm{myrs})\end{array}$ \\
\hline SC 1 vs. 2 & 0.084 & 0.014 & 4.2 & 0.7 & 4.9 & 0.8 & 6.0 & 1.0 \\
SC 1 vs. 3 & 0.222 & 0.030 & 11.1 & 1.5 & 13.1 & 1.8 & 15.9 & 2.1 \\
SC 1 vs. 4 & 0.208 & 0.028 & 10.4 & 1.4 & 12.2 & 1.6 & 14.9 & 2.0 \\
SC 1 vs. 5 & 0.085 & 0.014 & 4.3 & 0.7 & 5.0 & 0.8 & 6.1 & 1.0 \\
SC 2 vs. 3 & 0.217 & 0.029 & 10.9 & 1.5 & 12.8 & 1.7 & 15.5 & 2.1 \\
SC 2 vs. 4 & 0.190 & 0.025 & 9.5 & 1.3 & 11.2 & 1.5 & 13.6 & 1.8 \\
SC 2 vs. 5 & 0.049 & 0.009 & 2.5 & 0.5 & 2.9 & 0.5 & 3.5 & 0.6 \\
SC 3 vs. 4 & 0.117 & 0.018 & 5.9 & 0.9 & 6.9 & 1.1 & 8.4 & 1.3 \\
SC 3 vs. 5 & 0.218 & 0.030 & 10.9 & 1.5 & 12.8 & 1.8 & 15.6 & 2.1 \\
SC 4 vs. 5 & 0.181 & 0.024 & 9.1 & 1.2 & 10.6 & 1.4 & 12.9 & 1.7 \\
\hline \hline SC 1 vs. the rest & 0.117 & 0.016 & 5.9 & 0.8 & 6.9 & 0.9 & 8.4 & 1.1 \\
SC 2 vs. the rest & 0.100 & 0.014 & 5.0 & 0.7 & 5.9 & 0.8 & 7.1 & 1.0 \\
SC 3 vs. the rest & 0.134 & 0.018 & 6.7 & 0.9 & 7.9 & 1.1 & 9.6 & 1.3 \\
SC 4 vs. the rest & 0.099 & 0.013 & 5.0 & 0.7 & 5.8 & 0.8 & 7.1 & 0.9 \\
SC 5 vs. the rest & 0.082 & 0.012 & 4.1 & 0.6 & 4.8 & 0.7 & 5.9 & 0.9 \\
\hline
\end{tabular}


Table 2. Results of the neutrality tests for each sub-clade using CO1 data

\begin{tabular}{ccccc}
\hline Sub-clades & Tajima's $D$ & $P$-value & Fu's $F s$ & $P$-value \\
\hline 1 & -0.46217 & 0.326 & -4.10171 & 0.004 \\
2 & 0.95536 & 0.860 & 5.25412 & 0.981 \\
3 & -0.44615 & 0.372 & 1.58931 & 0.811 \\
4 & -1.56949 & 0.055 & -1.53469 & 0.047 \\
5 & -0.81734 & 0.132 & 0.96133 & 0.609 \\
\hline
\end{tabular}

Table 3. Pairwise $\Phi_{\mathrm{ST}}$ using CO1 sequences. $n=$ number of individuals used in analysis. All comparisons significant $(p<0.001)$. Refer Fig. 1 and Accessory Publication for site localities.

\begin{tabular}{ccccc}
\hline Sites $(n)$ & MA\&TCB & GC1\&2 & LH & BNP1\&2 \\
\hline MA\&TCB (10) & - & & & \\
GC1\&2 (12) & 0.77 & - & & \\
LH (11) & 0.87 & 0.98 & - & \\
BNP1\&2 (14) & 0.89 & 0.98 & 0.98 & - \\
LakeH (6) & 0.85 & 0.98 & 0.99 & 0.77 \\
\hline
\end{tabular}

Fig. 1. (B) Locations of Tenuibranchiurus collection sites in Queensland and New South Wales and their corresponding CO1 networks; diamonds = data from this study, circles $=$ data from past studies, broken circles = type localities. Size of haplotype circles is proportional to haplotype frequency. Maximum likelihood bootstrap phylograms showing the relationship between (A) CO1 haplotypes and (C) $16 \mathrm{~S}$ haplotypes, where colour shades correspond to sample location. Numbers on branches indicate ML bootstrap values, with parentheses the NJ and MP bootstrap values respectively. Refer to Accessory Publication for site localities (historical and this study). 


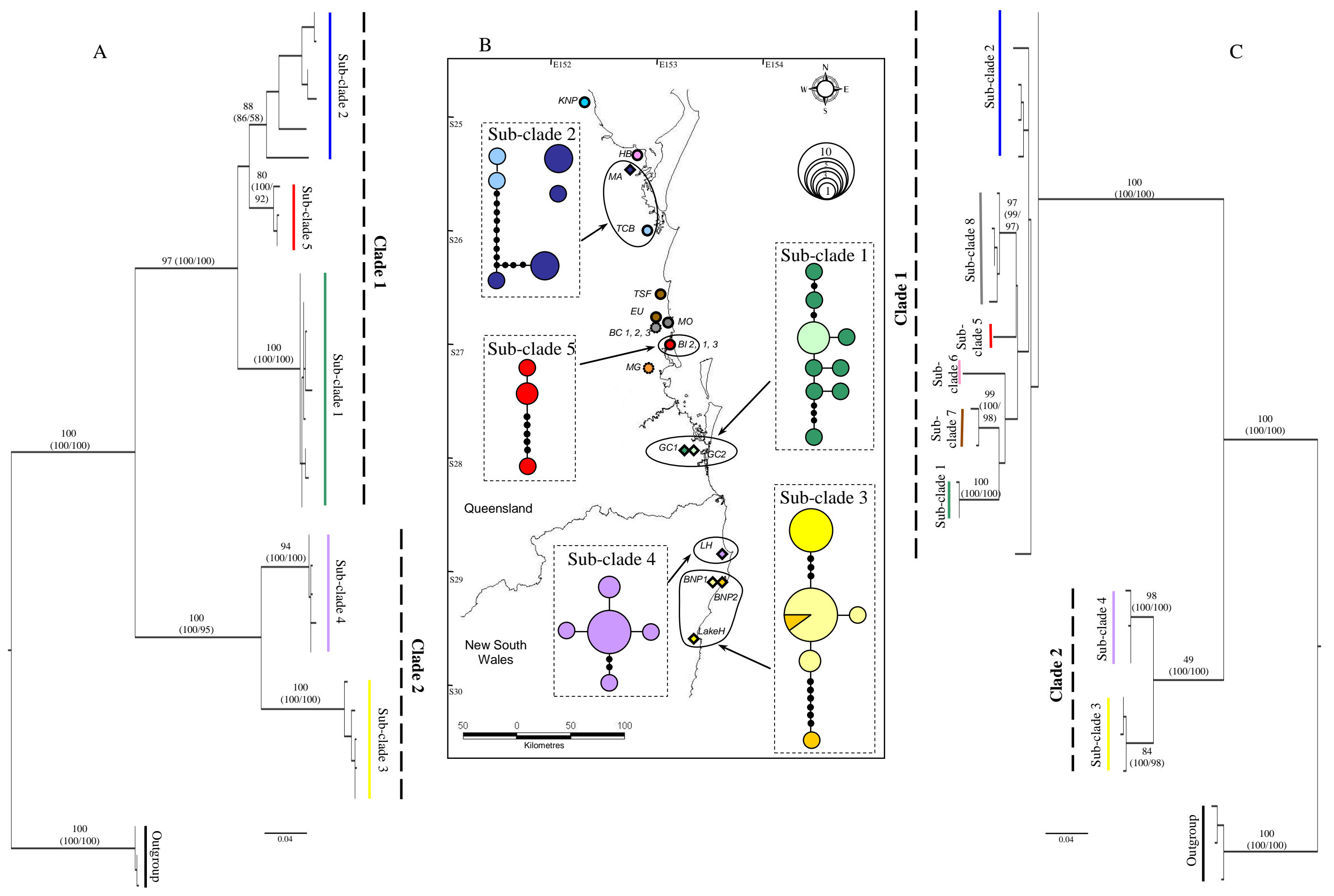


